\title{
Zinc zirconium phosphate as an efficient catalyst for chemoselective synthesis of 1,1-diacetates under solvent-free conditions
}

\author{
ABDOL R HAJIPOUR ${ }^{\mathrm{a}, \mathrm{b}, *}$ and HIRBOD KARIMI ${ }^{\mathrm{a}, \mathrm{c}}$ \\ ${ }^{a}$ Pharmaceutical Research Laboratory, Department of Chemistry, Isfahan University of Technology, \\ Isfahan 84156, IR, Iran \\ ${ }^{b}$ Department of Neuroscience, University of Wisconsin, Medical School, Madison, WI 53706-1532, USA \\ ${ }^{\mathrm{c}}$ Young Researchers and Elite Club, Shahreza Branch, Islamic Azad University, Shahreza, Iran \\ e-mail: haji@cc.iut.ac.ir
}

MS received 13 April 2015; revised 5 August 2015; accepted 13 August 2015

\begin{abstract}
In the present study, a mild, rapid, and efficient method for the protection of aldehydes with acetic anhydride (AA) in the presence of zinc zirconium phosphate (ZPZn) as a nano catalyst, at room temperature is reported. Selective conversion of aldehydes was observed in the presence of ketones. Under these conditions, different aldehydes bearing electron-withdrawing and electron-donating substituents were reacted with AA and the corresponding 1,1-diacetates (acylals) were obtained in high to excellent yields. The steric and electronic properties of the different substrates had a significant influence on the reaction conditions. Also, the deprotection of 1,1-diacetates has been achieved using this catalyst in water. This nanocatalyst was characterized by several physico-chemical techniques. It was recovered easily from the reaction mixture, regenerated and reused at least 7 times without significant loss in catalytic activity. This protocol has the advantages of easy availability, stability, reusability of the eco-friendliness, chemoselectivity, simple experimental and work-up procedure, solvent-free conditions and usage of only a stoichiometric amount of AA.
\end{abstract}

Keywords. Zinc zirconium phosphate; nanoparticles; heterogeneous catalysis; diacetate; solvent-free synthesis.

\section{Introduction}

The electrophilic nature of carbonyl groups is a dominant feature of their extensive chemistry. Selective protection and deprotection of aromatic or aliphatic carbonyl groups are essential steps in modern organic chemistry. ${ }^{1}$ The protection of aldehydes, as acetals, acylals, oxathioacetals, or dithioacetals, is a common practice for manipulation of other functional groups during multisteps synthesis. Geminal diacetates (acylals) are one of the essential carbonyl protecting groups due to their stability under neutral, basic and acidic conditions. Furthermore, they can be easily converted into parent aldehydes, which are frequently used as protecting groups for aldehydes. ${ }^{1,2}$ Besides, the acylals functionality can be converted into other useful functional groups by reaction with appropriate nucleophiles which are also useful intermediates in industries, such as cross linking agent for cellulose in cotton or used as stainbleaching agents. ${ }^{3-5}$ In addition, the preparation of 1,1-diacetates from the corresponding aldehydes, in the presence of ketones, can be very important due to

\footnotetext{
*For correspondence
}

their involvement in various natural products synthesis. ${ }^{3,4}$ Several reagents and catalysts have been reported for the synthesis of acylals from aldehydes using acetic anhydride (AA), such as SiPW-8, ${ }^{6} \mathrm{SiO}_{2} / \mathrm{B}\left(\mathrm{SO}_{4} \mathrm{H}\right)_{3},{ }^{7}$ S-CKT, ${ }^{8}$ SuSA,,${ }^{9}$ SBA-15-Ph-PrSO ${ }_{3} \mathrm{H}^{10}{ }^{10} \mathrm{Zr}\left(\mathrm{HSO}_{4}\right)_{4},{ }^{11}$ PEG- $\mathrm{SO}_{3} \mathrm{H}^{12}$ Sulphated Zirconia, ${ }^{13} \mathrm{SO}_{4}^{2-} / \mathrm{SnO}_{2},{ }^{14}$ ZSM-5-SO ${ }_{3} \mathrm{H},{ }^{15} \mathrm{PS} / \mathrm{TiCl}_{4},{ }^{16}$ Schiff base complex of $\mathrm{Cr}(\mathrm{III}),{ }^{17}$ Solid sulfuric acid $,{ }^{18} \mathrm{SBSSA},{ }^{19} \mathrm{CPTS}-\mathrm{HOAc},{ }^{20}$ $\mathrm{H}_{2} \mathrm{NSO}_{3} \mathrm{H}^{21} \mathrm{ZrCl}_{4},{ }^{22}$ Zeolite $\mathrm{Y},{ }^{23}[$ bmpy $] \mathrm{HSO}_{4},{ }^{24}[\mathrm{Hmim}]$ $\mathrm{HSO}_{4},{ }^{25}[$ mor $]$ HSO $\mathrm{HSO}_{4},{ }^{26} \mathrm{SiO}_{2}-\mathrm{SO}_{3} \mathrm{H},{ }^{27} \mathrm{P}_{2} \mathrm{O}_{5} / \mathrm{Al}_{2} \mathrm{O}_{3},{ }^{28}$ $\mathrm{RuCl}_{3} \cdot \mathrm{H}_{2} \mathrm{O},{ }^{29} \mathrm{H}_{6} \mathrm{P}_{2} \mathrm{~W}_{18} \mathrm{O}_{62} \cdot 24 \mathrm{H}_{2} \mathrm{O},{ }^{30}$ zirconium sulfophenyl phosphonate, ${ }^{31} \mathrm{La}\left(\mathrm{NO}_{3}\right)_{3} \cdot 6 \mathrm{H}_{2} \mathrm{O},{ }^{32}\left(\mathrm{NH}_{4}\right)_{3}$ $\mathrm{PW}_{12} \mathrm{O}_{40},{ }^{33} \mathrm{PBBS},{ }^{34} \mathrm{SbCl}_{3},{ }^{35} \mathrm{Cu}_{3 / 2} \mathrm{PMo}_{12} \mathrm{O}_{40} / \mathrm{SiO}_{2},{ }^{36}$ $\mathrm{Si}-[$ SbSipim $]\left[\mathrm{PF}_{6}\right],{ }^{37} \operatorname{DOWEX}(\mathrm{R}) 50 \mathrm{WX} 4,{ }^{38}[\mathrm{bmim}][\mathrm{Fe}$ $\left.\mathrm{Cl}_{4}\right],{ }^{39} \mathrm{Mo} / \mathrm{TiO}_{2}-\mathrm{ZrO}_{2},{ }^{40}$ Cyanuric chloride, ${ }^{41} \mathrm{CuSO}_{4}$. $5 \mathrm{H}_{2} \mathrm{O},{ }^{42} \quad \mathrm{H}_{3} \mathrm{PW}_{12} \mathrm{O}_{40},{ }^{43} \quad \mathrm{H}_{2} \mathrm{SO}_{4}$-silica, ${ }^{44}$ Supported $\mathrm{POM},{ }^{45}$ and $\mathrm{P}_{2} \mathrm{O}_{5} / \mathrm{SiO}_{2}{ }^{46,47}$ Although some of these methods have convenient protocols with good to high yields, some of these methods suffer at least from one of the following disadvantages: reaction under oxidizing conditions, use of harmful organic solvents, long reaction times, use of excess AA, unrecyclable catalysts, high cost, and high toxicity. Also, very few reports are applicable to both the synthesis as well as deprotection of 1,1-diacetates. ${ }^{14,15,22,31,48}$ 
$\alpha$-Zirconium phosphate (ZP) is one of the most important compounds in inorganic chemistry, and the layered structure of this compound has been used in different fields. ${ }^{49-51}$ The layered structure of ZP consists of zirconium ions in a semiplanar arrangement, located slightly above and below the mean plane, while each $\mathrm{Zr}^{4+}$ ion is connected through the oxygen atoms of phosphate groups from above and below. Three of the four oxygen atoms in the phosphate groups are bonded to three different zirconium atoms. The fourth oxygen atom of the phosphate groups that bonds to a proton, the free $-\mathrm{OH}$ group, is pointing into the interlayer region. ${ }^{50,51} \mathrm{ZP}$ behaves as a unique ion exchanger because of its exceptionally poor aqueous solubility, high thermal stability, resistance to radiation and abrasive properties. ${ }^{52,53}$ The $\mathrm{H}^{+}$of the $\mathrm{P}-\mathrm{OH}$ moiety in $\mathrm{ZP}$ can be exchanged for various other ions, which results in the enlargement of the interlayer distance. ${ }^{54-56} \mathrm{Sev}-$ eral studies pertaining to the successful exchange of the $\mathrm{H}^{+}$of the $\mathrm{P}-\mathrm{OH}$ group in $\mathrm{ZP}$ with various divalent and trivalent cations have been reported in the literature. ${ }^{57-62}$ It has also been reported that $\mathrm{ZP}$ possesses excellent selectivity towards $\mathrm{Pb}^{2+}, \mathrm{Zn}^{2+}$, and $\mathrm{Fe}^{3+}$ as an ion exchanger. ${ }^{63-65}$ Furthermore, ZP has been reported to exhibit antibacterial activity when it was loaded with $\mathrm{Cu}^{2+}, \mathrm{Zn}^{2+}$, or $\mathrm{Ce}^{3+}{ }^{60-62}$ Several reports have also appeared in the literature concerning the catalytic activities of ion exchanged materials of this type, including the use of copper zirconium phosphate $(\mathrm{ZPCu})$ as catalyst in the acetylation of alcohols and phenols and the use of zirconium phosphate-ferric chloride complex and potassium iron zirconium phosphate as catalyst in Friedel-Crafts reaction. ${ }^{66-72}$

To the best of our knowledge, there is no report available in the literature for using ZPZn as catalyst for the preparation of 1,1-diacetates from carbonyl compounds. Therefore, in continuation of our reports using various catalysts for the synthesis of 1,1-diacetates from aldehydes, ${ }^{25-29}$ we report a convenient, recyclable and chemoselective procedure for conversion of aldehydes to the corresponding acylals in the presence of AA. The reaction was easily carried out at room temperature under solvent-free condition with short reaction times for a wide range of aldehydes.

\section{Experimental}

\subsection{Catalyst synthesis}

All the reagents and solvents used in the current study were purchased from the Merck Chemical Company and used without further purification. The catalyst was prepared according to previously published procedures, with minor modifications. ${ }^{50,60-62} \mathrm{ZP}$ was prepared according to the following procedure. $\mathrm{ZrOCl}_{2} \cdot 8 \mathrm{H}_{2} \mathrm{O}$ $(5 \mathrm{~g})$ was heated at reflux in a solution of $\mathrm{H}_{3} \mathrm{PO}_{4}(50 \mathrm{~mL}$, $12 \mathrm{~mol} / \mathrm{L}$ ) for $24 \mathrm{~h}$. The resulting mixture was cooled to ambient temperature to give a suspension, which was filtered, and the filter cake was then washed with a solution of $\mathrm{H}_{3} \mathrm{PO}_{4}(0.1 \mathrm{~mol} / \mathrm{L})$ until the filtrate was free of chloride ions. In order to determine the presence of any chlorine ino in the filtrate, the silver nitrate test was used. The filter cake was then washed several times with distilled water until the $\mathrm{pH}$ of the filtrate was neutral. The solid was then collected and dried in an oven at $110^{\circ} \mathrm{C}$ for $24 \mathrm{~h} .^{50} \mathrm{ZPZn}$ was prepared through an ionexchange reaction. ${ }^{60-62}$ Briefly, ZP (3 g) was dispersed in deionized water $(50 \mathrm{~mL})$ at $50^{\circ} \mathrm{C}$, and the resulting suspension was treated with a solution of $\mathrm{Zn}(\mathrm{OAc})_{2}$ $\left(100 \mathrm{~mL}, 0.1 \mathrm{~mol} / \mathrm{L}\right.$ ) in water (excess amount of $\mathrm{Zn}^{2+}$ ). This mixture was then heated at reflux for $4 \mathrm{~d}$. It is noteworthy that the acetate ion performed effectively as a base to keep the hydrogen ion concentration in solution sufficiently low to achieve high loadings of the catalyst. $^{72}$ A complete exchange between the cations and the hydrogen ions of the $\mathrm{P}-\mathrm{OH}$ groups could not be achieved in less than $3 \mathrm{~d}$ or at temperatures below $80^{\circ} \mathrm{C}^{61}$ The resulting slurry was filtered hot to give a light white solid, which was washed with distilled water until no $\mathrm{Zn}^{2+}$ ions could be detected in the filtrate (i.e., until the filtrate was colorless). The solid product was then dried at $110^{\circ} \mathrm{C}$ for $8 \mathrm{~h}$ before being calcined at $600^{\circ} \mathrm{C}$ for $4 \mathrm{~h}$ to give the final product, $\mathrm{ZPZn}$, as a white solid (scheme 1).

\subsection{Catalyst characterization}

The chemical composition of the ZPZn catalyst was evaluated at different stages of the reaction (i.e., before and after the catalytic reaction) by ICP-OES using an Optima 7300 V ICP-OES spectrometer (PerkinElmer) (table 1). The samples were ground into a fine powder and analyzed by XRD on a Philips X'pert X-ray diffractometer. The specific surface areas of the samples were determined from their $\mathrm{N}_{2}$ adsorption-desorption isotherms

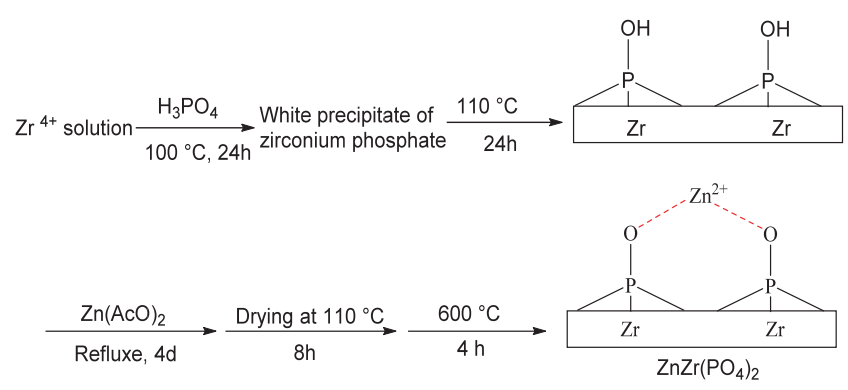

Scheme 1. Procedure for the preparation of ZPZn. 
Table 1. Elemental contents (\%) of ZPZn and physical properties of the catalysts before and after reaction.

\begin{tabular}{lccccccc}
\hline Entry & Sample & $\mathrm{Zn}$ & $\mathrm{O}$ & $\mathrm{Zr}$ & $\mathrm{P}$ & $\mathrm{BET}\left(\mathrm{m}^{2} / \mathrm{g}\right)$ & $\begin{array}{c}\text { Total acidity } \\
\left(\mathrm{mmol} \mathrm{NH}_{3} / \mathrm{g}\right)\end{array}$ \\
\hline 1 & $\mathrm{ZP}$ & - & 65.3 & 12.4 & 22.3 & 118.2 & 2.5 \\
2 & $\mathrm{ZPZn}$ & 12.1 & 54.1 & 12.3 & 21.5 & 102.4 & 1.6 \\
3 & $\mathrm{ZPZn}^{\mathrm{a}}$ & 12 & 54.3 & 12.2 & 21.5 & 102.1 & 1.52 \\
4 & $\mathrm{ZPZn}^{\mathrm{b}}$ & 8.7 & 59.2 & 12.1 & 20.0 & 96.4 & 1.05 \\
5 & ZPZn $^{\mathrm{c}}$ & 4.7 & 63.5 & 12 & 19.8 & 86.4 & 0.78 \\
\hline
\end{tabular}

${ }^{a}$ After the first cycle.

${ }^{\mathrm{b}}$ After the 6th cycle.

${ }^{c}$ After the 7th cycle.

using the Brunauer-Emmett-Teller (BET) method on a Quantachrome ChemBET 3000 instrument. Each sample was degassed at $400^{\circ} \mathrm{C}$ for $2 \mathrm{~h}$ before being analyzed to remove any adsorbed species from their surfaces. The BET surface areas of the materials were estimated from their $\mathrm{N}_{2}$ adsorption-desorption isotherms. The surface morphologies of the ZP and ZPZn materials were studied by SEM on a Philips XL scabbing electron microscope (Philips). TEM images of ZPZn were obtained on a CENTRA 100 TEM system (Zeiss).

\subsection{Typical procedure for preparation of 1,1-diacetates}

Typically, in a $25 \mathrm{~mL}$ round bottom flask, equipped with a magnetic stirrer, substrate $(5 \mathrm{mmol})$ and AA $(10 \mathrm{mmol})$ and catalyst $(1 \mathrm{~mol} \%)$ were transferred. The reaction mixture was stirred at room temperature for the specified time under solvent-free conditions. Samples were collected periodically and analyzed by gas chromatography (GC). After completion of the reaction, the mixture was diluted with $\mathrm{Et}_{2} \mathrm{O}$ and the catalyst was recovered by centrifuge. The organic layer was washed with $10 \% \mathrm{NaHCO}_{3}$ solution and then dried over anhydrous $\mathrm{CaCl}_{2}$. The solvent was evaporated under reduced pressure to give the corresponding pure 1,1-diacetate. The results and general experimental procedure are summarized in tables 2 and 3.

\subsection{Procedure for the deprotection of 1,1 diacetates to aldehyde}

A solution of 1,1-diacetate $(5 \mathrm{mmol})$ in water $(2 \mathrm{~mL})$ and ZPZn (1 mol\%) was introduced into a round bottom flask equipped with a magnetic stirrer and condenser at $80^{\circ} \mathrm{C}$. The reaction was monitored by GC. After the reaction, the mixture was diluted with $\mathrm{Et}_{2} \mathrm{O}$ and the catalyst was recovered by centrifuge. The organic layer was washed with water. The organic extracts were combined and washed with $10 \% \mathrm{NaHCO}_{3}$ and
Table 2. Conversion of benzaldehyde to its corresponding diacetate in different solvents and under solvent-free conditions in the presence of ZPZn.

\begin{tabular}{lccc}
\hline Entry & Solvent $^{\mathrm{a}}$ & ${\text { Yield }(\%)^{\mathrm{b}}}$ & Time (min) \\
\hline 1 & Diethylether & 51 & 90 \\
2 & Cyclohexane & 38 & 120 \\
3 & Dichloromethane & 56 & 90 \\
4 & Acetonitrile & 67 & 120 \\
5 & Ethylacetate $_{6}$ & 55 & 120 \\
6 & Solvent-free $^{\mathrm{c}}$ & 90 & 15 \\
\hline
\end{tabular}

a The reaction was carried out in $5 \mathrm{ml}$ of solvents at reflux conditions.

$\mathrm{b}$ The yields refer to isolated pure products.

$\mathrm{c}$ The reaction was carried out at r.t.

dried over anhydrous $\mathrm{CaCl}_{2}$. The solvent was evaporated under reduced pressure to give the corresponding aldehyde.

\subsection{Recyclability studies of catalyst}

To examine the recyclability of the catalyst, the used ZPZn was recovered from the reaction media and reused. For recycling, after the first use, the catalyst was separated from the reaction mixture by centrifugation, washed sequentially with ethanol and water before being dried at $110^{\circ} \mathrm{C}$ for $2 \mathrm{~h}$, and then activated at $450^{\circ} \mathrm{C}$ for $2 \mathrm{~h}$.

\section{Results and discussion}

\subsection{Catalyst characterization}

The ICP-OES analyses of ZP and ZPZn are shown in table 1 . The results obtained in the current study for ZPZn were compared with those reported. ${ }^{60-62}$ Our results revealed that there was a negligible leach of zinc ions into the reaction media after the reaction (i.e., following the first use of the catalyst). 
Table 3. Preparation of acylals in the presence of $\mathrm{ZPZn}$ under solvent-free conditions at r.t.

$$
\left.\underset{(5 \mathrm{mmol})}{\mathrm{R}-\mathrm{CHO}}+\underset{(10 \mathrm{mmol})}{\mathrm{Ac}_{2} \mathrm{O}} \stackrel{\text { SPZn }(1 \mathrm{~mol} \%)}{\stackrel{\text { Solvent-free, r.t }}{\longrightarrow}} \text { R-CH(OAc) }\right)_{2}
$$

\begin{tabular}{|c|c|c|c|c|c|}
\hline \multirow[b]{2}{*}{ Entry } & \multirow[b]{2}{*}{ Substrate } & \multirow[b]{2}{*}{ Time (min) } & \multirow[b]{2}{*}{ Yeild $(\%)^{\mathrm{a}}$} & \multicolumn{2}{|c|}{ M.p. $\left({ }^{\circ} \mathrm{C}\right)$ or B.p. $\left({ }^{\circ} \mathrm{C}\right)$} \\
\hline & & & & Found & Reaported [ref] \\
\hline 1 & $\mathrm{C}_{6} \mathrm{H}_{5} \mathrm{CHO}$ & 15 & 90 & $43-45$ & $44-45^{6-10}$ \\
\hline 2 & $4-\mathrm{Me}-\mathrm{C}_{6} \mathrm{H}_{4} \mathrm{CHO}$ & 30 & 90 & $80-82$ & $81-82^{6-10}$ \\
\hline 3 & $2-\mathrm{Me}-\mathrm{C}_{6} \mathrm{H}_{4} \mathrm{CHO}$ & 45 & 85 & $64-66$ & $64-669^{13,81,82}$ \\
\hline 4 & $2-\mathrm{MeO}-\mathrm{C}_{6} \mathrm{H}_{4} \mathrm{CHO}$ & 45 & 85 & $68-80$ & $73-74^{6-10}$ \\
\hline 5 & $3-\mathrm{MeO}-\mathrm{C}_{6} \mathrm{H}_{4} \mathrm{CHO}$ & 20 & 89 & Oil & $\mathrm{Oil}^{6-10}$ \\
\hline 6 & $4-\mathrm{MeO}-\mathrm{C}_{6} \mathrm{H}_{4} \mathrm{CHO}$ & 30 & 84 & $65-66$ & $64-65^{6-10}$ \\
\hline 7 & 3,4-di-MeO- $\mathrm{C}_{6} \mathrm{H}_{4} \mathrm{CHO}$ & 45 & 84 & $70-72$ & $72-74^{6-10}$ \\
\hline 8 & 2,5-di-MeO- $\mathrm{C}_{6} \mathrm{H}_{4} \mathrm{CHO}$ & 45 & 83 & $107-108$ & $110^{6-10}$ \\
\hline 9 & $4-\mathrm{OH}-\mathrm{C}_{6} \mathrm{H}_{4} \mathrm{CHO}^{\mathrm{b}}$ & 120 & 85 & 90-92 & $89-90^{6-10}$ \\
\hline 10 & $2-\mathrm{OH}-\mathrm{C}_{6} \mathrm{H}_{4} \mathrm{CHO}^{\mathrm{b}}$ & 180 & 82 & $101-102$ & $101-103^{6-10}$ \\
\hline 11 & $2-\left(\mathrm{CH}_{3}\right)_{2} \mathrm{CH}-\mathrm{C}_{6} \mathrm{H}_{4} \mathrm{CHO}$ & 75 & 83 & $58-60$ & - \\
\hline 12 & $2-\left(\mathrm{CH}_{3}\right)_{3} \mathrm{C}-\mathrm{C}_{6} \mathrm{H}_{4} \mathrm{CHO}$ & 120 & 74 & $68-70$ & - \\
\hline 13 & $2-\mathrm{Cl}-\mathrm{C}_{6} \mathrm{H}_{4} \mathrm{CHO}$ & 15 & 95 & $51-52$ & $52-53^{6-10}$ \\
\hline 14 & $3-\mathrm{Cl}-\mathrm{C}_{6} \mathrm{H}_{4} \mathrm{CHO}$ & 10 & 95 & $64-65$ & $64-65^{6-10}$ \\
\hline 15 & 2,6-di-Cl- $\mathrm{C}_{6} \mathrm{H}_{4} \mathrm{CHO}$ & 20 & 85 & $89-90$ & $88-90^{6-10}$ \\
\hline 16 & 4-Cl- $\mathrm{C}_{6} \mathrm{H}_{4} \mathrm{CHO}$ & 10 & 91 & $81-82$ & $82-83^{6-10}$ \\
\hline 17 & $4-\mathrm{Br}_{-} \mathrm{C}_{6} \mathrm{H}_{4} \mathrm{CHO}$ & 10 & 94 & $93-95$ & $92-95^{6-10}$ \\
\hline 18 & $2-\mathrm{Br}-\mathrm{C}_{6} \mathrm{H}_{4} \mathrm{CHO}$ & 15 & 91 & $80-82$ & $80^{83}$ \\
\hline 19 & $2-\mathrm{NO}_{2}-\mathrm{C}_{6} \mathrm{H}_{4} \mathrm{CHO}$ & 20 & 88 & $91-93$ & $90-91^{8,9,18,27}$ \\
\hline 20 & $4-\mathrm{NO}_{2}-\mathrm{C}_{6} \mathrm{H}_{4} \mathrm{CHO}$ & 10 & 95 & $124-126$ & $125-127^{6-10}$ \\
\hline 21 & $2-\mathrm{NC}-\mathrm{C}_{6} \mathrm{H}_{4} \mathrm{CHO}$ & 10 & 96 & $74-76$ & $76-77^{11}$ \\
\hline 22 & $4-\mathrm{NC}-\mathrm{C}_{6} \mathrm{H}_{4} \mathrm{CHO}$ & 10 & 96 & $100-101$ & $100-102^{6-10}$ \\
\hline 23 & $2-\mathrm{F}_{-} \mathrm{C}_{6} \mathrm{H}_{4} \mathrm{CHO}$ & 10 & 90 & $24-26$ & $25-268^{83}$ \\
\hline 24 & $4-\mathrm{F}-\mathrm{C}_{6} \mathrm{H}_{4} \mathrm{CHO}$ & 10 & 95 & $50-52$ & $50-52^{8,24,28}$ \\
\hline 25 & 4-(N,N-di-MeN)- $\mathrm{C}_{6} \mathrm{H}_{4} \mathrm{CHO}$ & 180 & - & - & - \\
\hline 26 & Furfural & 30 & 70 & $52-53$ & $52-53^{6-10}$ \\
\hline 27 & Cinnamaldehyde & 10 & 92 & $84-86$ & $84-85^{6-10}$ \\
\hline 28 & Hexanal & 45 & 77 & Oil & $\mathrm{Oil}^{6-10}$ \\
\hline 29 & 2-butenal & 45 & 77 & Oil & $\mathrm{Oil}^{6-10}$ \\
\hline 30 & $\mathrm{C}_{6} \mathrm{H}_{4} \mathrm{CH}_{2} \mathrm{CH}_{2} \mathrm{CHO}$ & 20 & 71 & Oil & $\mathrm{Oil}^{6-10}$ \\
\hline 31 & Isobutyraldehyde & 45 & 71 & Oil & $\mathrm{Oil}^{6-10}$ \\
\hline 32 & Cyclohexanone & 180 & - & - & - \\
\hline 33 & $\mathrm{C}_{6} \mathrm{H}_{5} \mathrm{COCH}_{3}$ & 180 & - & - & - \\
\hline 34 & $4-\mathrm{NO}_{2} \mathrm{C}_{6} \mathrm{H}_{4} \mathrm{COCH}_{3}$ & 180 & - & - & - \\
\hline 35 & $4-\mathrm{NO}_{2}-\mathrm{C}_{6} \mathrm{H}_{4} \mathrm{CHO}^{\mathrm{c}}$ & 180 & - & - & - \\
\hline
\end{tabular}

${ }^{\text {a }}$ All products were identified by their M.p., IR, GC-MS and ${ }^{1} \mathrm{H}$ NMR spectra with authentic samples.

${ }^{\mathrm{b}} \mathrm{AA}(15 \mathrm{mmol})$.

${ }^{\mathrm{c}}$ The reactions was performed in the absence of $\mathrm{ZPZn}$ at $60^{\circ} \mathrm{C}$.

Figure 1 shows the powder XRD patterns of the ZP and ZPZn materials. The results show some characteristic reflections in the $2 \theta$ range of $5^{\circ}-40^{\circ}$. The diffraction peak in $\mathrm{ZP}$ at $2 \theta \sim 12^{\circ}$ was assigned to a $\mathrm{d}_{002}$ basal spacing of $7.5 \AA$ between the planes, which was consistent with the patterns previously reported for $\mathrm{ZP}$ and its derivatives with a hexagonal crystal system. ${ }^{50}$ It shows that the d-spacing of the (002) plane of ZPZn had increased, which indicated that the $\mathrm{Zn}^{2+}$ ions had intercalated into the interlayer of $\mathrm{ZP}$ and increased the $\mathrm{d}_{002}$ basal interlamellar spacing of ZP from 7.5 to $8.7 \AA$.
It is well known that the ionic radii of $\mathrm{Zn}^{2+}(0.74 \AA)$ and hydrated $\mathrm{Zn}^{2+}(2.16 \AA)$ are smaller than the basal spacing of ZP $(7.5 \AA) .{ }^{73,74}$ The crystal structure of ZPZn was affected by the exchange of zinc ions. When the zinc ions were introduced into the $\mathrm{ZP}$, the crystallinity gradually decreased. Its XRD pattern shows a layered material, slightly disordered, that, however, clearly shows the harmonics of the first $d_{002}$ reflection. These results therefore indicated that $\mathrm{Zn}^{2+}$ ions had inserted into the interlayer of $\mathrm{ZP}$ and increased the basal spacing of the modified ZP after the exchange. ${ }^{60-62}$ Taken together, 
these data indicated that ZPZn had been formed successfully. The XRD pattern of the ZPZn catalyst after the 7th run showed that the basal spacing of $\mathrm{ZP}$ was about $9.5 \AA$, which was only a little larger than that of the fresh ZPZn catalyst. This increase may have occurred because of the presence of less $\mathrm{Zn}^{2+}$ on the surface of ZP, and an increase in the number of water molecules between the layers following the seventh run (i.e., $\mathrm{Zn}^{2+}$ ions may have been washed off during the regeneration of the catalyst, table 1). Our findings showed good agreement with earlier reports. ${ }^{60-62}$

Figure 2 shows the $\mathrm{N}_{2}$ adsorption-desorption isotherm of $\mathrm{ZPZn}$, as a representative example, in the relative pressure range $\left(\mathrm{P} / \mathrm{P}_{0}\right)$ of $0.1-1.0$. The surface area of ZPZn was determined to be $102.4 \mathrm{~m}^{2} / \mathrm{g}$. The isotherm for ZPZn shows three adsorption stages. The first of these stages was observed at $\mathrm{P} / \mathrm{P}_{0}<0.46$, whereas the second stage was observed in the range of $0.46<\mathrm{P} / \mathrm{P}_{0}$ $<0.95$, and the third stage was observed at higher relative pressures $\left(\mathrm{P} / \mathrm{P}_{0}>0.95\right)$. The $\mathrm{N}_{2}$ adsorption-desorption isotherm of ZPZn exhibited a typical "type IV" isotherm shape with a distinct hysteresis loop,

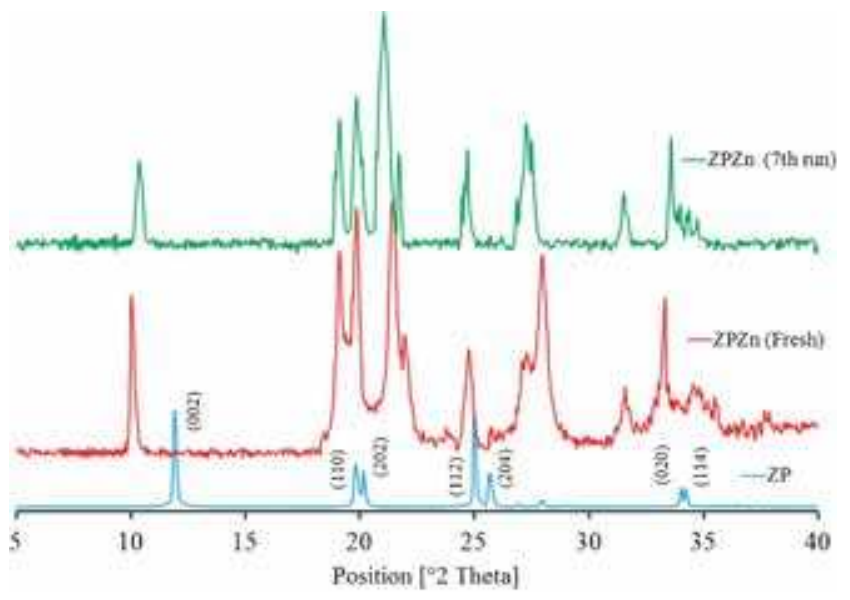

Figure 1. XRD patterns of powder ZP (down), ZPZn fresh (middle) and after the 7 th run (up).

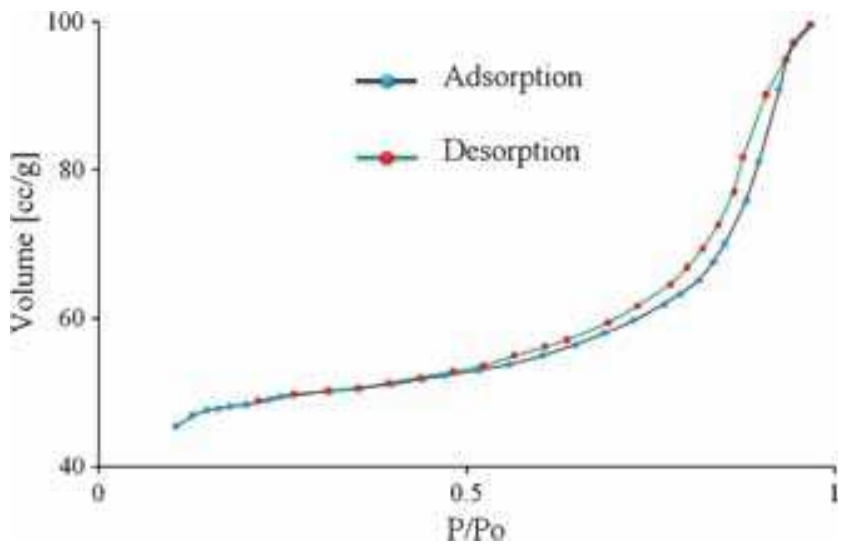

Figure 2. $\mathrm{N}_{2}$ adsorption-desorption isotherm of $\mathrm{ZPZn}$. which is characteristic of a mesoporous material. ${ }^{75}$ The hysteresis loop (type H3) is associated with the occurrence of capillary condensation in the mesopores, which indicates the presence of a mesoporous structure in the ZPZn catalyst. The observed increase in adsorption at the higher $\mathrm{P} / \mathrm{P}_{0}$ value indicated the presence of larger mesopores in the sample. ${ }^{61-66}$ The surface area of ZPZn after the 7 th run was found to be $86.4 \mathrm{~m}^{2} / \mathrm{g}$.

The nature of the acid sites of ZP and ZPZn was studied by IR spectroscopy using pyridine as a probe molecule. Pyridine adsorption was used to determine the acidic sites using FTIR. Prior to the measurements, $20 \mathrm{mg}$ of a catalyst was pressed in self-supporting disc and activated in the IR cell attached to a vacuum line at $350^{\circ} \mathrm{C}$ for $4 \mathrm{~h}$. The adsorption of pyridine was performed at $150^{\circ} \mathrm{C}$ for $30 \mathrm{~min}$. The excess of probe molecules was further evacuated at $150^{\circ} \mathrm{C}$ for $0.5 \mathrm{~h}$. The adsorption-evacuation was repeated several times until no change in the spectra was observed (figure 3). The main bands observed over the samples are assigned according to the literature data. ${ }^{76,77}$ Pyridine adsorbed FTIR spectra of the ZPZn show the strong bands at 1632 and $1541 \mathrm{~cm}^{-1}$, indicating typical pyridinium ion. The band at $1488 \mathrm{~cm}^{-1}$ is a combination band between those at 1541 and $1444 \mathrm{~cm}^{-1}$, corresponding to Brønsted and Lewis acid sites, respectively. The origin of Brønsted acidity of the ZP is due to the presence of $\mathrm{P}-\mathrm{OH}$ groups, ${ }^{78,79}$ while the main acitidy of $\mathrm{ZPZn}$ is due to its Lewis acid sites $\left(\mathrm{Zn}^{2+}\right)$ (figure 3). Figure 3 shows the Py-FTIR spectrum of the catalyst after the 7th run. It clearly indicates that the replacement of $\mathrm{Zn}^{2+}$ on the surface of the catalyst with $\mathrm{H}^{+}$during the catalyst regeneration process has reduced the number of Lewis acid sites (band at $1444 \mathrm{~cm}^{-1}$ was reduced). Conversely, the amount of Brønsted acid sites was increased (band at $1632 \mathrm{~cm}^{-1}$ was increased).

Total acidity of the samples was determined by temperature-programmed desorption of ammonia (TPD$\mathrm{NH}_{3}$ ) with a Quantachrome ChemBET 3000. Before the

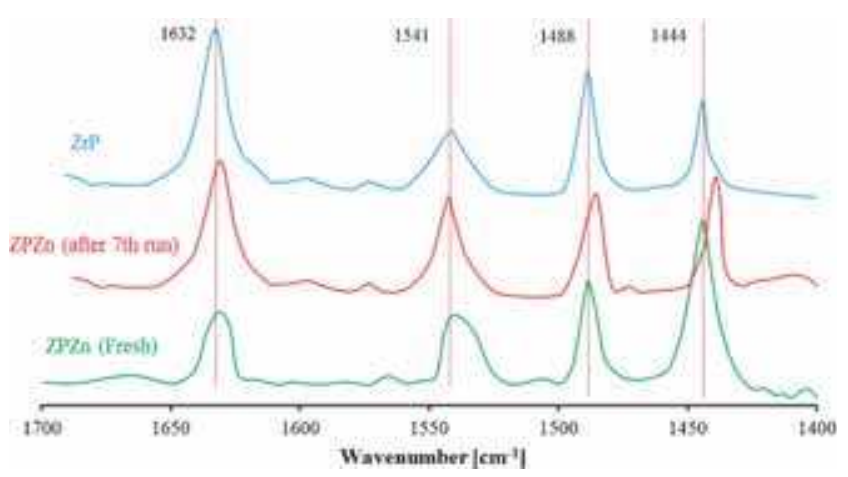

Figure 3. Pyridinedesorbed FTIR spectra of ZPZn (Fresh and after the 7 th run) and $\mathrm{ZrP}$. 
adsorption of ammonia, the samples were pre-treated in $\mathrm{He}$ at $250^{\circ} \mathrm{C}$ for $30 \mathrm{~min}$ and then, $1 \mathrm{~h}$ at $350^{\circ} \mathrm{C}$ and cooled to $100^{\circ} \mathrm{C}$. Then ammonia was adsorbed on the samples for $1 \mathrm{~h}$. The TPD- $\mathrm{NH}_{3}$ was carried out between 150 and $550^{\circ} \mathrm{C}$, at $10^{\circ} \mathrm{C} / \mathrm{min}$, and analyzed by a thermal conductivity detector (TCD) for continuous monitoring of the desorbed ammonia. TPD- $\mathrm{NH}_{3}$ provides a quantitative estimation of the total number of acid sites and the distribution of acid strengths. Because of the strong basicity of $\mathrm{NH}_{3}$ gas, it was expected that all acid sites on the catalysts interact with $\mathrm{NH}_{3}$. The total amount of $\mathrm{NH}_{3}$ desorbed after saturation permits the quantification of the number of acid sites on the surface, while the position of the peak, desorption temperature, indicates the strength of the catalyst, i.e., higher temperature of desorption, stronger is the acid strength. The TPD-NH $\mathrm{NH}_{3}$ curves of $\mathrm{ZPZn}$ are shown in figure 4 $\mathrm{ZPZn}$ desorbed ammonia in a wide range of temperatures from 212 to $538^{\circ} \mathrm{C}$, which mostly correspond to the medium and strong acidic sites. The $\mathrm{NH}_{3}$ desorption peak at temperatures below $250^{\circ} \mathrm{C}$ belongs to the physisorption/chemisorptions of $\mathrm{NH}_{3}$ molecules on weak acidic sites. The peak at about $250-450^{\circ} \mathrm{C}$ shows the existence of intermediate strength acidic sites and finally the peak at $450-538^{\circ} \mathrm{C}$ demonstrates the presence of strong acidic sites on the surface of ZPZn. Figure 4 shows that the desorption of ammonia starts at almost $212^{\circ} \mathrm{C}$, centered at $317^{\circ} \mathrm{C}$. The $\mathrm{NH}_{3}$-TPD curves subsequently decreased with further increase in temperature and almost complete at $538^{\circ} \mathrm{C}$. This indicates that $\mathrm{ZPZn}$ contains a considerable number of acid sites which is attributed to the presence of $\mathrm{Zn}^{2+}$ groups on the surface of zirconium phosphate layers and make it suitable solid acid catalyst. ${ }^{66}$ The extent of desorptions is found to be ca. $1.6 \mathrm{mmol} \mathrm{NH}_{3} / \mathrm{g}$ of catalyst. A TPD experiment was carried out after the 7 th cycle by recovering the catalyst, in order to magnify the difference from the fresh catalysts (table 1).

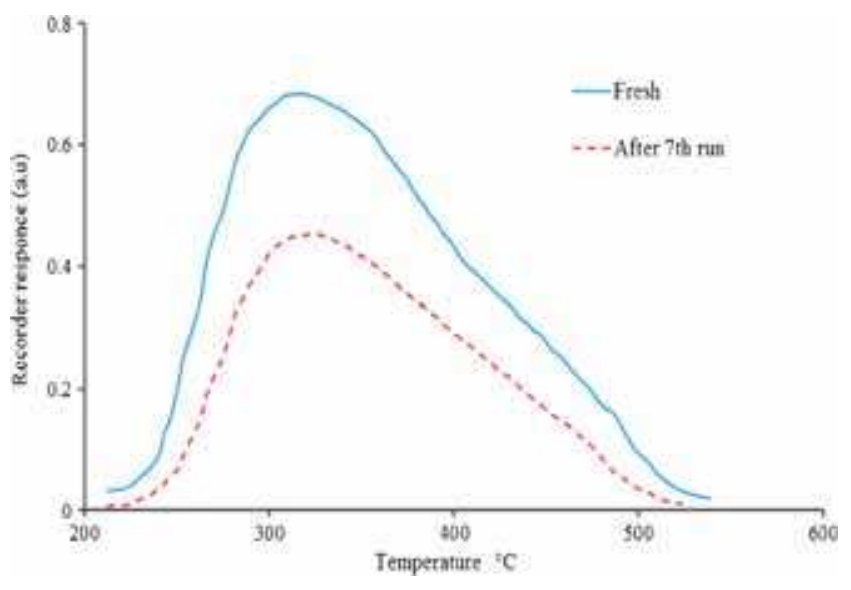

Figure 4. $\mathrm{NH}_{3}-\mathrm{TPD}$ profile of $\mathrm{ZPZn}$.
The surface morphology of the ZP and ZPZn was studied by SEM (SEM, Philips XL) (figure 5). The SEM image of ZP (figure 5(a)) revealed the presence of hexagonal plates with well-defined shapes and very smooth surfaces. Figures 5(b) and (c) (different magnification) show the SEM images of ZPZn. These images revealed that the structure of $\mathrm{ZPZn}$ was less ordered than that of ZP, and that the ZPZn particles had aggregated to form both sheets and spheres of different shapes and sizes. ${ }^{60,61,66}$

Figure 6 shows the TEM (CENTRA 100, Zeiss) images of ZPZn. It shows that ZPZn catalyst retained the original morphology of ZP (layered structure) and that the particles were approximately $150 \mathrm{~nm}$ in size.

These images also showed nanoparticles of different sizes on the smooth surface of the ZP. The presence of metallic crystal nanoparticles on the surface of $\mathrm{ZP}$ indicated that the zinc deposited on the surface of the $\mathrm{ZP}$ had agglomerated. Similar observations have also been reported for copper, zinc, and cerium with $\mathrm{ZP}^{61,62,72}$ Figure 5(d) and 6(c,d) show the SEM and TEM images of the catalyst after several regenerations, respectively. All these images showed that the sheets and particles had conglomerated to a much greater extent following the 7 th run because of the process used to regenerate the catalyst.

\subsection{Synthesis of 1,1-diacetates and expected mechanism}

In order to find the most appropriate reaction conditions and evaluate the catalytic efficiency of ZPZn on the protection of aldehydes to the corresponding 1,1diacetates, we tried to convert benzaldehyde $(5 \mathrm{mmol})$ to its corresponding acylal with ZPZn (1 mol\%) and AA $(10 \mathrm{mmol})$ in various solvents and also under solventfree conditions. We observed that the yield of the reaction under solvent-free condition is higher and the reaction time is shorter as compared to the other methods, table 2.

Therefore, to establish the generality and scope of the method, we employed the above conditions for conversion of various aldehydes (aromatic, heterocyclic, aliphatics and $\alpha, \beta$-unsaturated aldehydes) to the corresponding diacetates, table 3 . Both aromatic and aliphatic aldehydes react smoothly with AA to afford the corresponding 1,1-diacetates in good to excellent yields in short reaction times at room temperature (table 3, entries 1-23), which are, in general, similar or higher than those described in the literature. ${ }^{6-47}$ The reactions did not proceed in the absence of ZPZn even under heating conditions (table 3, entry 27). Under these reaction conditions, various functional groups (Me, isopropyl, 

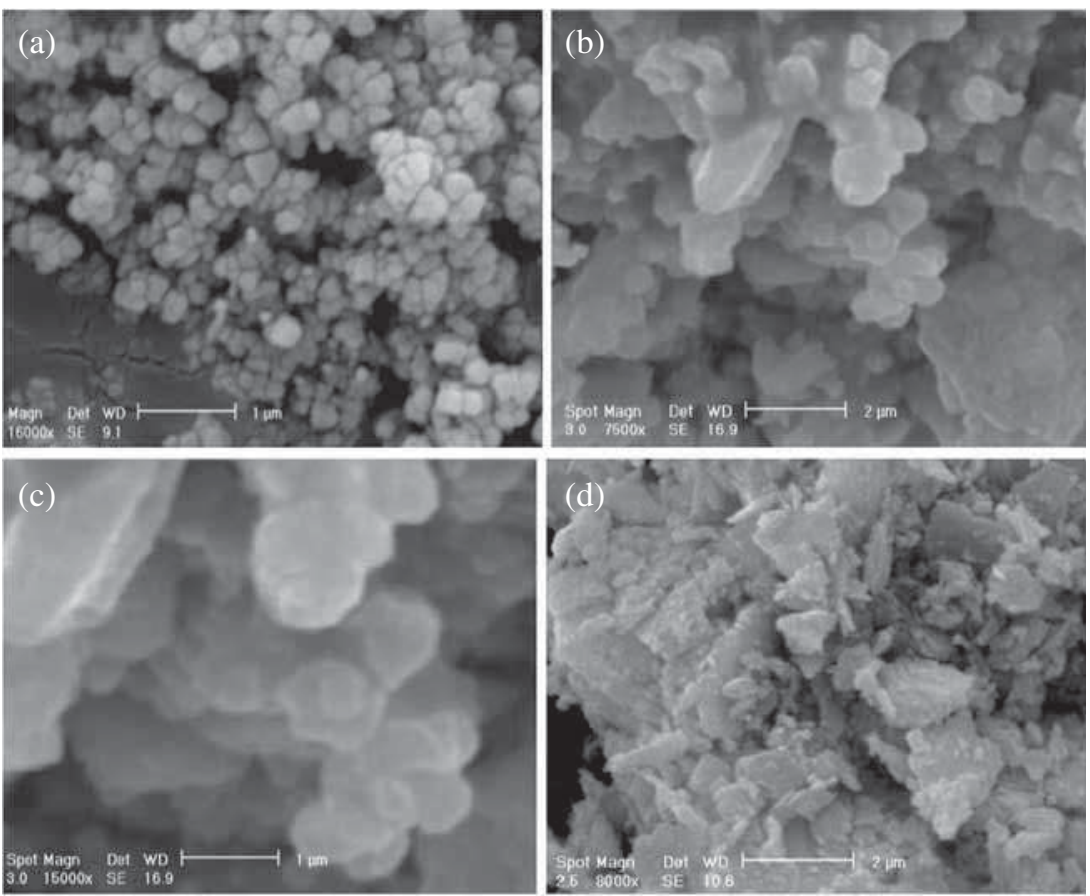

Figure 5. SEM images of regular morphology of prepared ZP (a), ZPZn fresh (b, c) and after the 7th run (d).
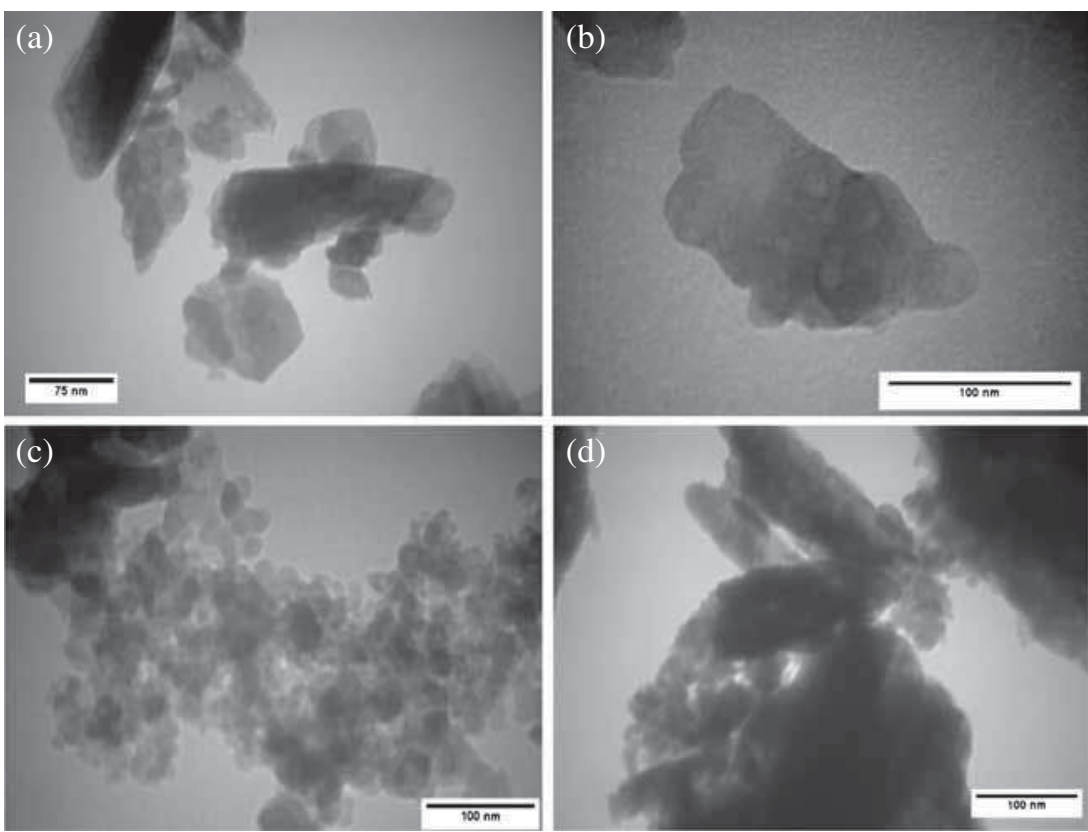

Figure 6. TEM images of regular morphology of prepared ZPZn fresh $(a, b)$ (different magnification) and after the 6th (c) and the 8th run (d).

t-butyl, $\mathrm{OMe}, \mathrm{OH}, \mathrm{F}, \mathrm{Cl}, \mathrm{Br}, \mathrm{CN}, \mathrm{NO}_{2}$ ) were tolerated. The electronic properties of the substituents on the aromatic aldehydes have a major effect on the reaction yield and time. The aldehydes with electron-withdrawing groups $\left(\mathrm{NO}_{2}, \mathrm{CN}, \mathrm{F}, \mathrm{Cl}\right.$ and $\left.\mathrm{Br}\right)$, afforded the corresponding diacetates in higher yields (table 3, entries 13-24). ${ }^{80}$ But, aldehydes bearing electron-donating groups (Me, isopropyl, t-butyl, and $\mathrm{OMe}$ ) gave the corresponding 1,1-diacetates in lower yields and longer reaction times (table 3, entries 2-12). This may be due to the reduced electrophilicity of the aldehyde group as a result of the electron-rich nature of the phenyl ring to which the aldehyde is attached. Also, the reaction rate was found to be dependent on steric crowding surrounding the aldehyde group. Thus, the presence of substitutes at the para or the meta position (table 3, entries 
$2,5,6,9,14,16,17,20,22$ and 24) made the reaction faster with better yields than those with substitutes at the ortho position (table 3, entries 3,4,8,10,13,15,18,19,21 and 23). Moreover, aldehydes with hindered alkyl substitutes, 2-isopropylbenzaldehyde and 2-(tert-butyl)benzaldehyde, produced the corresponding acylals in longer reaction times and lower yields (table 3, entries 11,12).

The acid-sensitive compounds such as furfural and cinnamaldehyde were also protected as 1,1-diacetates in good yields without any side products (table 3, entries 26 and 27). We investigated the reaction of 2-hydroxybenzaldehyde and 4-hydroxybenzaldehyde under above conditions (table 3, entries 9 and 10); it should be mentioned that the phenolic group was also protected as acetate in hydroxyl containing aromatic aldehyde under such conditions ( 3 equiv. of $\mathrm{Ac}_{2} \mathrm{O}$ ). 4-(dimethylamino) benzaldehyde failed to give 1,1-diacetate under the same conditions which may be due to the electron donation of dimethylamino group (table 3 , entry 25). The explanation for this result may be due to the strong electron donating properties of the dimethylamino group which will reduce the reactivity. ${ }^{21}$ Moreover, the protocol could also equally work with aliphatic aldehydes (table 3, entries 28-31). Because of aldol condensation as a competitive reaction, the yields of corresponding acylals of aliphatic aldehydes were low. Ketones proved completely resistant to acylal synthesis with AA under these reaction conditions. ${ }^{21}$ Cyclohexanone, acetophenone, and 4-nitroacetophenone were checked for the reactivity. No diacetate formation was observed for these compounds, neither under room temperature nor reflux conditions (table 3, entries 32-35). Encouraged by this result, we suggest that the chemoselective protection of aldehydes in the presence of ketones can be achieved by this method (scheme 2). We found that benzaldehyde was converted to the related gem-diacetate while the acetophenone remained unaffected.
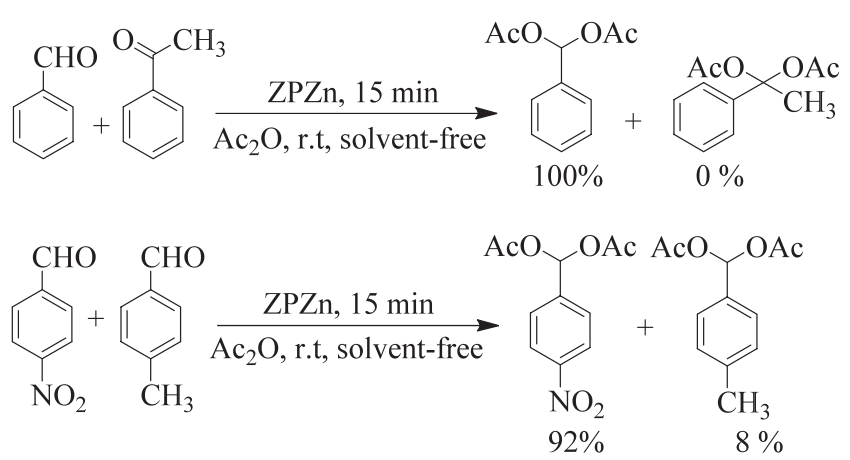

Scheme 2. Competitive acylal formation of aldehydes in the presence of ZPZn.
In addition to these results, we further studied the possibility of deprotection of resulting acylals in this catalytic system by addition of water as a green solvent. Indeed, deprotection of phenylmethylene diacetate to the benzaldehyde was performed by treatment of acylals in water at $80^{\circ} \mathrm{C}$. By this procedure, related acylal has been completely transformed into benzaldehyde in a short reaction time (scheme 3 ).

On the basis of literature studies, a plausible catalytic cycle for the regeneration of ZPZn has been proposed. As outlined in scheme 4, the possible mechanism of this reaction may be involvement of either intermolecular or intramolecular transfer of the second acetate group after the initial attack by AA. We suggest that ZPZn, as a Lewis acid, increases the electrophilicity of the carbonyl group on the aldehyde. Then, AA attacks com-

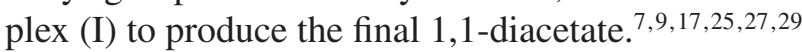

We were interested in studying the reusability of the catalyst because of economic and environmental aspects. Hence, the reaction of benzaldehyde with AA was chosen as a model reaction in the presence of regenerated $\mathrm{ZPZn}$ under the optimum reaction conditions and the results are summarized in table 4. Used ZPZn gave a similar yield of product as the fresh catalyst till the 7th cycle. The lowered activity of the used catalyst sample confirms the deactivation of catalyst during the reaction.

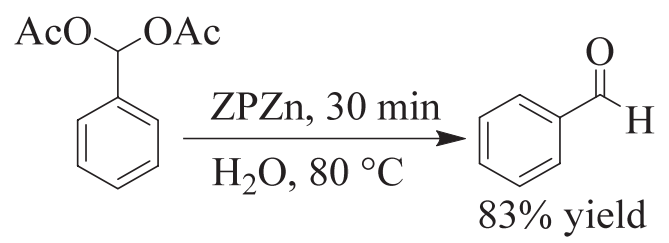

Scheme 3. Cleavage of acylal to benzaldehyde in water catalyzed by ZPZn.

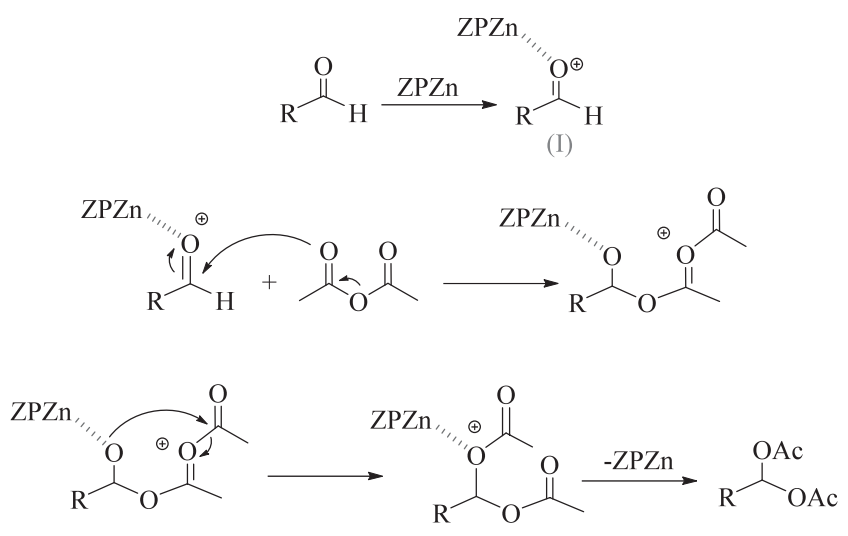

Scheme 4. Plausible mechanism. 
The regenerated catalyst was characterized for its chemical composition by elemental analysis. The elemental composition of the catalyst remained almost unchanged upto its 7th run, although the amount of zinc in the catalyst was reduced by almost $60 \%$ compared with the first run (table 1). As it can be seen from this table, no significant change in composition of the catalyst was observed after the first use. There was a negligible leach of $\mathrm{Zn}^{2+}$ into the reaction media after the reaction (table 1 entry 2,3). Also, as it is presented in table 4 , the activity of the catalyst almost remained intact till the 7th run. But, after the 7th run, the decomposition of the catalyst was changed $\left(\mathrm{Zn}^{2+}\right.$ was washed from the zirconium phosphate surface during the catalyst regeneration), which caused a reduction of the product yield down to $68 \%$. We believe that the catalytic activity of ZPZn is due to its Lewis acid sites (scheme 4) and when these active sites were reduced, the catalytic activity was reduced as well. Also, another reason for less activity of ZPZn after the 7th run is probably because of catalyst agglomeration after several thermal regenerations (figure 6).

In order to compare the catalytic potentiality of ZPZn nanoparticles with some recently reported procedures in the literature, we have shown the results of the synthesis of acylal from benzaldehyde in the presence of various

Table 4. Catalyst re-usage under the optimum reaction conditions for 1,1-diacetate synthesis.

\begin{tabular}{lccccccccc}
\hline Substrate $^{\mathrm{a}}$ & Fresh & run 1 & run 2 & run 3 & run 4 & run 5 & run 6 & run 7 & run 8 \\
\hline $\mathrm{C}_{6} \mathrm{H}_{5} \mathrm{CHO}$ & 90 & 90 & 90 & 89 & 88 & 88 & 85 & 84 & 68 \\
\hline
\end{tabular}

${ }^{\text {a }}$ Reaction conditions: $\mathrm{C}_{6} \mathrm{H}_{5} \mathrm{CHO}(5 \mathrm{mmol})$, AA (10 mmol), catalyst (1 mol\%), r.t. and $15 \mathrm{~min}$.

Table 5. Comparison of the effect of catalysts for 1,1-diacetate synthesis from benzaldehyde.

\begin{tabular}{|c|c|c|c|c|}
\hline Catalyst $^{\mathrm{a}}$ & $\mathrm{Ac}_{2} \mathrm{O}(\mathrm{mmol})$ & Time (min) & Yield \% & Ref. \\
\hline $\mathrm{SiO}_{2} / \mathrm{B}\left(\mathrm{SO}_{4} \mathrm{H}\right)_{3}$ & 2 & 4 & 97 & 7 \\
\hline $\mathrm{S}-\mathrm{CKT}$ & 5 & 5 & 96 & 8 \\
\hline SuSA & 2 & 12 & 98 & 9 \\
\hline SBA-15-Ph-PrSO ${ }_{3} \mathrm{H}$ & 1.2 & 5 & 100 & 10 \\
\hline $\mathrm{Zr}\left(\mathrm{HSO}_{4}\right)_{4}$ & 3 & 5 & 90 & 11 \\
\hline $\mathrm{PEG}_{-} \mathrm{SO}_{3} \mathrm{H}$ & 10 & 15 & 89 & 12 \\
\hline Sulphated Zirconia $^{\mathrm{b}}$ & 2.5 & 5 & 99 & 13 \\
\hline $\mathrm{SO}_{4}^{2-} / \mathrm{SnO}_{2}$ & 2 & 15 & 97 & 14 \\
\hline $\mathrm{ZSM}-5-\mathrm{SO}_{3} \mathrm{H}$ & 1 & 1 & 97 & 15 \\
\hline $\mathrm{PS} / \mathrm{TiCl}_{4}^{\mathrm{c}}$ & 1.2 & 40 & 93 & 16 \\
\hline Schiff base complex of $\mathrm{Cr}$ (III) & 3 & 15 & 96 & 17 \\
\hline Solid sulfuric acid & 15 & 5 & 83 & 18 \\
\hline SBSSA & 15 & 4 & 84 & 19 \\
\hline CPTS-HOAc & 4 & 42 & 92 & 20 \\
\hline $\mathrm{H}_{2} \mathrm{NSO}_{3} \mathrm{H}$ & 3 & 60 & 90 & 21 \\
\hline $\mathrm{ZrCl}_{4}$ & 3 & 30 & 90 & 22 \\
\hline Zeolite Y & 3 & 180 & 90 & 23 \\
\hline [bmpy] $\mathrm{HSO}_{4}^{\mathrm{d}}$ & 3 & 5 & 97 & 24 \\
\hline$[\mathrm{Hmim}] \mathrm{HSO}_{4}$ & 2 & 25 & 90 & 25 \\
\hline$[\mathrm{morH}] \mathrm{HSO}_{4}$ & 2 & 3 & 85 & 26 \\
\hline $\mathrm{SiO}_{2}-\mathrm{SO}_{3} \mathrm{H}$ & 4 & 25 & 90 & 27 \\
\hline $\mathrm{P}_{2} \mathrm{O}_{5} / \mathrm{Al}_{2} \mathrm{O}_{3}$ & 2.5 & 45 & 87 & 28 \\
\hline $\mathrm{RuCl}_{3} \cdot \mathrm{H}_{2} \mathrm{O}$ & 6 & 10 & 76 & 29 \\
\hline $\mathrm{La}\left(\mathrm{NO}_{3}\right)_{3} \cdot 6 \mathrm{H}_{2} \mathrm{O}$ & 2.2 & 90 & 90 & 32 \\
\hline$\left(\mathrm{NH}_{4}\right)_{3} \mathrm{PW}_{12} \mathrm{O}_{40}$ & 2 & 90 & 98 & 33 \\
\hline $\mathrm{ZPZn}$ & 2 & 15 & 90 & This work \\
\hline $\mathrm{ZP}$ & 3 & 20 & 85 & This work \\
\hline
\end{tabular}

\footnotetext{
a Reaction conditions: r.t., solvent-free.

${ }^{\mathrm{b}}$ Reaction temperature: $0^{\circ} \mathrm{C}$.

${ }^{c} \mathrm{CH}_{2} \mathrm{Cl}_{2}$ as solvent.

${ }^{\mathrm{d}}$ Ultrasonic irradiation, $30^{\circ} \mathrm{C}$.
} 
catalysts with respect to the amounts of AA, reaction time and the yield of the products (table 5). The results show that, ZPZn is an equally competitive or more efficient catalyst for this reaction with regard to reaction conditions and yield.

The better efficacy of ZPZn nanoparticles in solventfree synthesis of 1,1-diacetate from aldehydes might be due to the presence of Lewis acid sites $\left(\mathrm{Zn}^{2+}\right)$ on the surface of the catalyst. Moreover, this procedure offers advantages over some of the methodologies in terms of efficiency, deprotection, as well as protection, reusability of the catalyst and we found that ZPZn is a selective catalyst in solvent-free conditions, which thus, makes it environmentally more acceptable.

\section{Conclusions}

In summary, in this paper, we have reported a mild, solvent-free and efficient protocol for the protection of aldehydes for their conversion to the corresponding 1,1diacetates. ZPZn was used for this reaction at room temperature. This method is selective for the preparation of 1,1-diacetates from aldehydes in the presence of ketones. Also, 1,1-diacetates can be conveniently deprotected by using ZPZn in water. Other advantages of this catalyst are good to excellent yields and reusability of the catalyst. Further applications of this catalyst to other transformations are currently under investigation.

\section{Acknowledgments}

We gratefully acknowledge the funding support received for this project from the Isfahan University of Technology (IUT), IR Iran.

\section{References}

1. Wuts P G and Greene T W 2006 In Greene's protective groups in organic synthesis 4th edn (New York: John Wiley)

2. Kochhar K S, Bal B S, Deshpande R P, Rajadhyaksha S N and Pinnick H W 1983 J. Org. Chem. 481765

3. Van Heerden F R, Huyser J J, Williams D B G and Holzapfel C W 1998 Tetrahedron Lett. 395281

4. Frick Jr J G and Harper Jr R J 1984 J. Appl. Polym. Sci. 291433

5. Yadav J S, Subba Reddy B V and Srihari P 2001 Synlett 673

6. Wang J, Yan L, Qian G, Yang K, Liu H and Wang X 2006 Tetrahedron Lett. 478309

7. Sajjadifar S and Rezayati S 2014 Chem. Pap. 68531

8. Zheng Y J, Li J, Lu J J, Jia Y C and Li B L 2013 Chem. J. Chin. Univ. 342738

9. Shirini F and Khaligh N G 2013 Chin. J. Catal. 34695
10. Zareyee D, Moosavi S M and Alaminezhad A $2013 \mathrm{~J}$. Mol. Catal. A: Chem. 378227

11. Mirjalili B F, Zolfigol M A, Bamoniri A and Sheikhan N 2006 J. Chin. Chem. Soc. 53955

12. Zong Y X, Wang J K, Niu Y Y, Li Z L, Song Z E, Quan Z J, Wang X C, Yue G R and Pan Y 2013 Chin. Chem. Lett. 24140

13. Palacios G L N, Cruz G D Y, Lomas R L, González Z E, Ulibarri G and Negrón S G E 2009 Molecules 144065

14. Satam J R and Jayaram R V 2007 Catal. Commun. 8 1414

15. Massah A R, Kalbasi R J and Shafiei A 2012 Monatsh. Chem. 143643

16. Rahmatpour A and Mohammadian S 2013 C. R. Chim. 16912

17. Esmaeilpour M, Sardarian A R and Javidi J 2012 Appl. Catal. A. $\mathbf{4 4 5} 359$

18. Brojeni S P, Baghernejad M, Saberi D and Niknam K 2013 Green. Chem. Lett. Rev. 669

19. Niknam K, Saberi D and Sefat M N 2009 Tetrahedron Lett. $\mathbf{5 0} 4058$

20. Wang M, Song Z, Gong H and Jiang H 2008 Synth. Commun. 38961

21. Jin T S, Sun G, Li Y W and Li T S 2002 Green Chem. 4 255

22. Smitha G and Reddy C S 2003 Tetrahedron 599571

23. Ballini R, Bordoni M, Bosica G, Maggi R and Sartori G 1998 Tetrahedron Lett. 397587

24. Borikar S P and Daniel T 2011 Ultrason. Sonochem. 18 928

25. Hajipour A R, Khazdooz L and Ruoho A E 2008 Catal. Commun. 989

26. Hajipour A R, Nasreesfahani Z and Ruoho A E 2008 Org. Prep. Proced. Int. $\mathbf{4 0} 385$

27. Hajipour A R, Zarei A, Khazdooz L, Mirjalili B B F, Sheikhan N, Zahmatkesh S and Ruoho A E 2005 Synthesis 3644

28. Hajipour A R, Zarei A and Ruoho A E 2007 Tetrahedron Lett. 482881

29. Sheikhan N, Mirjalili B F, Hajipour A and Bamoniri A 2008 Acta Chim. Slov. 55209

30. Romanelli G P, Thomas H J, Baronetti G T and Autino J C 2003 Tetrahedron Lett. 441301

31. Curini M, Epifano F, Marcotullio M C, Rosati O and Nocchetti M 2002 Tetrahedron Lett. 432709

32. Srinivasulu M, Suryakiran N, Rajesh K, Malla Reddy S and Venkateswarlu Y 2008 Synth. Commun. 38 1753

33. Satam J R and Jayaram R V 2008 Synth. Commun. 38 595

34. Ghorbani-Vaghei R, Amiri M, Moshfeghifar N, Veisi H and Akbari Dadamahaleh S 2009 J. Iran. Chem. Soc. 6 754

35. Xu R, Zhang J, Tian Y and Zhou J 2009 J. Iran. Chem. Soc. 6443

36. Fazaeli R and Aliyan H 2008 Chin. J. Catal. 2910

37. Kang L, Cai Y and Cheng L 2013 Monatsh. Chem. 144 247

38. Asl P A and Setamdideh D 2014 J. Chin. Chem. Soc. 61 940

39. Wang D S, Li G Y and Peng Y Q 2009 J. Chin. Chem. Soc. 56834 
40. Reddy B M, Sreekanth P M and Khan A 2004 Synth. Commun. 341839

41. Bandgar B P, Joshi N S and Kamble V T 2007 J. Chin. Chem. Soc. $\mathbf{5 4} 489$

42. Heravi M M, Taheri S, Bakhtiari K and Oskooie H A 2006 Monatsh. Chem. 1371075

43. Firouzabadi H and Jafari A 2005 J. Iran. Chem. Soc. 2 85

44. Pourmousavi S and Kazemi S 2012 Monatsh. Chem. 143 917

45. Fazaeli R, Tangestaninejad S and Aliyan H 2007 Appl. Catal. A. 318218

46. Eshghi H and Shafieyoon P 2005 J. Chin. Chem. Soc. 52 155

47. Eshghi H and Hassankhani A 2012 J. Iran. Chem. Soc. 9467

48. Zhang Z-H 2005 Monatsh. Chem. 1361191

49. Gan H, Zhao X, Song B, Guo L, Zhang R, Chen C, Chen J, Zhu W and Hou Z 2014 Chin. J. Catal. 351148

50. Sun L, Boo W J, Sue H J and Clearfield A 2007 New J. Chem. 3139

51. Hajipour A R and Karimi H 2014 Mater. Lett. 116356

52. Alhendawi H, Brunet E, Juanes O, Idhair S, Hammouda H, Payan E and De Victoria Rodriguez M 2014 J. Chem. Sci. 1261721

53. Alhendawi H 2014 J. Chem. Sci. 126975

54. Khare S and Chokhare R 2012 J. Mol. Catal. A: Chem. 353138

55. Wang Q, Yu J, Liu J, Guo Z, Umar A and Sun L 2013 Sci. Adv. Mater. 5469

56. Allulli S, Ferragina C, La Ginestra A, Massucci M A, Tomassini N and Tomlinson A A 1976 J. Chem. Soc., Dalton Trans. 2115

57. Patel H and Chudasama U 2007 J. Chem. Sci. 11935

58. Naik A H, Deb S B, Chalke A B, Saxena M K, Ramakumar K L, Venugopal V and Dharwadkar S R 2010 J. Chem. Sci. 12271

59. Giannoccaro P, Gargano M, Fanizzi A, Ferragina C and Aresta M 2005 Appl. Catal. A. 28477

60. Cai X, Dai G J, Tan S Z, Ouyang Y, Ouyang Y S and Shi Q S 2012 Mater. Lett. 67199

61. Yang Y, Dai G, Tan S, Liu Y, Shi Q and Ouyang Y 2011 J. Rare Earths 29308
62. Dai G, Yu A, Cai X, Shi Q, Ouyang Y and Tan S 2012 J. Rare Earths 30820

63. Zhang Q R, Du W, Pan B C, Pan B J, Zhang W M, Zhang Q J, Xu Z W and Zhang Q X 2008 J. Hazard. Mater. 152 469

64. Costantino U, Szirtes L, Kuzmann E, Megyeri J and Lázár K 2001 Solid State Ionics 141359

65. Khare S and Chokhare R 2011 J. Mol. Catal. A: Chem. 34483

66. Wang X Y, Hua W M, Yue Y H and Gao Z 2013 Chem. J. Chin. Univ. 341913

67. Gawande M, Deshpande S, Sonavane S and Jayaram R 2005 J. Mol. Catal. A: Chem. 241151

68. Pylinina A and Mikhalenko I 2013 Russ. J. Phys. Chem. A 87372

69. Pylinina A and Mikhalenko I 2011 Russ. J. Phys. Chem. A 852109

70. Hajipour A, Karimi H and Karimzadeh M 2014 Monatsh. Chem. 1451461

71. Hajipour A R and Karimi H 2014 Chin. J. Catal. 35 1529

72. Hajipour A R and Karimi H 2014 Chin. J. Catal. 35 1982

73. Liu C C, Wang M K, Chiou C S, Li Y S, Yang C Y and Lin Y A 2009 J. Hazard. Mater. 171386

74. Tan S Z, Zhang K H, Zhang L L, Xie Y S and Liu Y L 2008 Chin. J. Chem. 26865

75. Sing K S 1985 Pure Appl. Chem. 57603

76. Tyagi B, Chudasama C D and Jasra R V 2006 Appl. Clay Sci. 3116

77. Corma A 1995 Chem. Rev. 95559

78. Sinhamahapatra A, Sutradhar N, Roy B, Tarafdar A, Bajaj H C and Panda A B 2010 Appl. Catal. A 385 22

79. Sinhamahapatra A, Sutradhar N, Roy B, Pal P, Bajaj H C and Panda A B 2011 Appl. Catal. B 103378

80. Hammett L P 1937 J. Am. Chem. Soc. 5996

81. Nouri Sefat M, Deris A and Niknam K 2011 Chin. J. Chem. 292361

82. Shirini F, Mamaghani M and Seddighi M 2013 Catal. Commun. 3631

83. Rahman M A and Jahng Y 2007 Eur. J. Org. Chem. 2007 379 